\title{
Oxyphytosterols are present in plasma of healthy human subjects
}

\author{
André Grandgirard ${ }^{1 *}$, Lucy Martine ${ }^{1}$, Luc Demaison ${ }^{1}$, Catherine Cordelet ${ }^{1}$, Corinne Joffre ${ }^{1}$, \\ Olivier Berdeaux ${ }^{1}$ and Etienne Semon ${ }^{2}$ \\ ${ }^{1}$ Unité de Nutrition Lipidique, INRA, 17 rue Sully, BP 86510, 21065 DIJON cedex, France \\ ${ }^{2}$ Laboratoire de Recherches sur les Arômes, INRA, Dijon, France
}

(Received 5 June 2003 - Revised 15 September 2003 - Accepted 16 September 2003)

\begin{abstract}
The oxidised derivatives of phytosterols (oxyphytosterols) were identified in plasma samples from thirteen healthy human volunteers,




nol), (24R)-methylcholestan-3 $\beta, 5 \alpha, 6 \beta$-triol (campestanetriol) and (24R)-ethylch olest-5-en-3 $\beta$-ol-7-one(7-ketositosterol). The amounts of these oxyphytosterols in plasma varied from 4.8 to $57.2 \mathrm{ng} / \mathrm{ml}$. There are two possibilities concerning the origin of these compounds. First, they could come from the small amounts of oxyphytosterols in food. Second, they could originate from the in vivo oxidation of phytosterols in plasma. Very few data actually exist concerning these compounds. Their identification in human samples suggests that further research is necessary in this field.
\end{abstract}

Oxyphytosterols: Phytosterols: Human plasma: Mass spectrometry

Plant sterols (phytosterols) display hypocholesterolaemic properties due to their effective inhibition of cholesterol absorption (Piironen et al. 2000). These compounds recently gained much interest; the esterification of phytosterols has allowed their incorporation in large quantities into margarines without changing their physical properties. For the last few years, numerous studies have been carried out showing the effectiveness of dietary phytosterols and of phytosterols-derived stanols in improving lipoprotein profiles in hypercholesterolaemic and normocholesterolaemic subjects (Piironen et al. 2000). This led to an increasing availability of phytosterol-enriched foods, as spreads or yoghurts. As a consequence, this will probably enhance the level of plant sterols in human circulation.

These plant sterols can be oxidised, as can cholesterol (Daly et al. 1983). The oxycholesterols, oxidised sterols obtained from cholesterol, have been extensively studied during the last 30 years; they exhibit many important biological properties including the modulation of cholesterol biosynthesis and metabolism (Guardiola et al. 1996; Janowski et al. 1996). These compounds are also suspected to be involved in atherosclerosis (Peng et al. 1991; GarciaCruset et al. 2002). Some of them are synthesised in vivo (Breuer \& Bjorkhem, 1995), but they can also be formed in foods (Addis, 1986) and absorbed (Emanuel et al. 1991; Osada et al. 1994; Diczfalusy, 2002). Concerning the phytosterol oxides (oxyphytosterols), very few data are available. In some studies, small quantities were identified in foods (Lee et al. 1985; Nourooz-Zadeh \& Appelqvist, 1992; Dutta, 1997; Dutta \& Appelqvist, 1997; Dutta \& Savage, 2002). In a recent experiment (Grandgirard et al. 1999), it was observed that a small quantity of these oxyphytosterols are absorbed by the intestine in rats. However, it was not known if these compounds were present in the tissues of healthy man. The oxides of plant sterols have only been described in two pathological situations. An old study mentioned that $\alpha$ - and $\beta$-epoxides of sitosterol were observed in the plasma of a patient with Waldenström's macroglobulinaemia (Brooks et al. 1983). A very recent work (Plat et al. 2001) allowed the detection of large levels of oxyphytosterols $(4.67 \mu \mathrm{g} / \mathrm{ml})$ in the serum of phytosterolaemic patients. In this later study, no oxyphytosterols were identified in the serum of control subjects. The present study was conducted to determine if small amounts of such compounds could be identified in the plasma of healthy human volunteers.

\section{Experimental procedures}

Reagents

Pyridine was from Sigma (L'Isle d'Abeau, France). It was dehydrated and maintained on $4 \AA$ molecular sieves. (25R)-cholest-5-en-3 $\beta, 26$-diol (27-hydroxycholesterol) was

\footnotetext{
Abbreviations: Campestanetriol, (24R)-methylcholestan-3 $\beta, 5 \alpha, 6 \beta$-triol; $\alpha$-epoxysitostanol, (24R)-5 $\alpha, 6 \alpha$-epoxy-24-ethylcholestan-3 $\beta$-ol; $\beta$-epoxysitostanol,

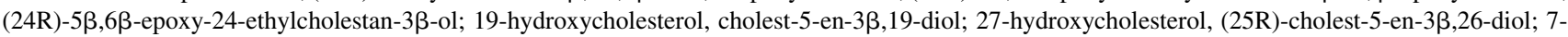
ketositosterol, (24R)-ethylcholest-5-en-3 $\beta$-ol-7-one; sitostanetriol, (24R)-ethylcholestan-3 $\beta, 5 \alpha, 6 \beta$-triol; TBME, tert-butyl methyl ether; TMSE, trimethylsilyl ether; TMSOH, hydroxytrimethylsilyl fragment.

* Corresponding author: Dr André Grandgirard, fax + 333806932 23, email grandgi@ dijon.inra.fr
} 
provided by Steraloids (Wilton, NH, USA). The oxyphytosterols were synthesised and characterised in a previous study (Grandgirard et al. 1999). Cholest-5-en-3ß,19-diol (19-hydroxycholesterol) and the other oxysterol standards were from Sigma (L'Isle d'Abeau, France). Butylated hydroxytoluene, tert-butyl methyl ether (TBME) and EDTA were obtained from Merck (Darmstadt, Germany). The silylation reagent bis-trimethylsilyl-trifluoroacetamide with $1 \%$ trimethylchlorosilane was from Pierce (Rockford, IL, USA). The other solvents were obtained from SDS (Peypin, France) and were distilled before use.

\section{Experiment and oxysterols analysis}

Blood samples of $20 \mathrm{ml}$ were collected from thirteen healthy human fasting volunteers (three women and ten men; aged 27 to 58 years; three of them were smokers) onto EDTA. The plasma was immediately obtained by centrifugation. The entire plasma obtained (more than $10 \mathrm{ml}$ ) was used for further analyses. The lipids were rapidly extracted using the method of Moilanen \& Nikkari (1981) modified by adding $0.05 \%$ butylated hydroxytoluene as antioxidant. After the addition of 19-hydroxycholesterol as the internal standard, the lipids were saponified for $1 \mathrm{~d}$, in the dark, under $\mathrm{N}_{2}$, at room temperature, using $1 \mathrm{M}$-ethanolic potassium hydroxide $(10 \mathrm{ml})$. After adding $20 \mathrm{ml}$ purified water, non-saponifiable matter was extracted two times by $20 \mathrm{ml}$ dichloromethane. The two dichloromethanolic fractions were gathered and washed several times with water until neutral $\mathrm{pH}$ was reached. This fraction was then redissolved in $500 \mu \mathrm{l}$ hexane-TBME (90:10, v/v) and purified by solid-phase extraction on silica cartridges (LC-Si, $3 \mathrm{ml}, 500 \mathrm{mg}$; Supelco, L'Isle d'Abeau, France) using successively $35 \mathrm{ml}$ hexaneTBME (90:10, v/v) and $15 \mathrm{ml}$ hexane-TBME (80:20, v/v). As recommended by Lai et al. (1995), a vacuum manifold (Supelco) was used to ensure a regular solvent flow rate of $0.6 \mathrm{ml} / \mathrm{min}$ through the cartridge. The oxysterols were then obtained with $5 \mathrm{ml}$ acetone. After the evaporation of solvents, the samples were redissolved in $200 \mu \mathrm{l}$ anhydrous pyridine and $200 \mu \mathrm{l}$ bis-trimethylsilyl-trifluoroacetamide containing $1 \%$ added trimethylchlorosilane. The trimethylsilyl ether (TMSE) derivatives were obtained by heating for $30 \mathrm{~min}$ at $60^{\circ} \mathrm{C}$. The reagents were evaporated under $\mathrm{N}_{2}$ and the residue dissolved in hexane for gas chromatographic analysis.

\section{Gas chromatography-mass spectrometry}

The TMSE derivatives were analysed by GC-MS using a 5890 Hewlett-Packard (Les Ulis, France) gas chromatograph coupled to a 5970 mass selective detector. The carrier gas was He. The injection was made in the splitless mode. A $30 \mathrm{~m} \times 0.25 \mathrm{~mm}$ internal diameter HP-5 column (Hewlett-Packard) was used. The thickness of the film was $0.25 \mu \mathrm{m}$. After $1 \mathrm{~min}$ at $50^{\circ} \mathrm{C}$, the oven temperature was raised at $20^{\circ} \mathrm{C} / \mathrm{min}$ until $270^{\circ} \mathrm{C}$, and then reached $290^{\circ} \mathrm{C}$ at $1^{\circ} \mathrm{C} / \mathrm{min}$. The oven temperature remained at $290^{\circ} \mathrm{C}$ during $35 \mathrm{~min}$ until the end of the analysis. The transfer line was operated at $290^{\circ} \mathrm{C}$. The mass spectrometer was operated at an ionisation energy of $70 \mathrm{eV}$.
Mass spectra were recorded between 50 and 700 atomic mass units. Quantitative analyses were performed by $\mathrm{GC}-\mathrm{MS}$ in the selected ion monitoring mode, using the $\mathrm{m} / \mathrm{z} 353$ (19-hydroxycholesterol; internal standard), 431 ((24R)-ethylcholestan-3 $\beta, 5 \alpha, 6 \beta$-triol; sitostanetriol), 470 ((24R)-methylcholestan-3 $\beta, 5 \alpha, 6 \beta$-triol; campestanetriol), 500 ((24R)-ethylcholest-5-en-3 $\beta$-ol-7-one; 7-ketositosterol) and 502 ((24R)-5 $3,6 \beta$-epoxy-24-ethylcholestan$3 \beta$-ol ( $\beta$-epoxysitostanol) and (24R)-5 $\alpha, 6 \alpha$-epoxy-24ethylcholestan-3 $\beta$-ol $(\alpha$-epoxysitostanol)). Using these methods, the detection limits were comprised between 0.4 and $0.9 \mathrm{ng}$.

\section{Use of ${ }^{2} \mathrm{H}$-labelled cholesterol for monitoring sterol oxide} formation during analysis

A human plasma sample was analysed for phytosterols using a common method (GC quantification of the TMSE derivatives of the unsaponifiable fraction) (Giacometti, 2001). The value obtained for sitosterol $(2.09 \mathrm{mg} / \mathrm{l})$ was used for monitoring the eventual formation of artifact oxyphytosterols during analysis. So, $20 \cdot 9 \mu \mathrm{g}$ cholesterol-2,2,3,4,4,6-d 6 (CDN Isotopes, Pointe Claire, Quebec, Canada) were added to $10 \mathrm{ml}$ human plasma. The level of ${ }^{2} \mathrm{H}$ labelling was $98 \%$ and was checked by GC-MS before analysis. The analysis was made two times. The method used was identical to that described before for oxyphytosterols. In MS, the $\mathrm{m} / \mathrm{z}$ ions 462, 480, 552 and 478 were checked for hydroxycholesterols, epoxycholesterols, cholestanetriol and 7-ketocholesterol, respectively.

\section{Use of campesterol and sitosterol for evaluating sterol oxide formation during analysis}

A blend of phytosterols (ICN, Orsay, France) containing $51.3 \%$ sitosterol, $28.5 \%$ campesterol, $10 \%$ stigmasterol, $6.5 \%$ brassicasterol and $1.5 \% \Delta 5$-avenasterol, was submitted to four successive crystallisations in acetone. The obtained product was purified two times on silica cartridges, in order to get rid of the eventual oxyphytosterols. It contained $69.4 \%$ campesterol, $28.1 \%$ sitosterol, $1 \%$ brassicasterol and $0.9 \%$ stigmasterol. This product was used to make another checking of the absence of artifact oxyphytosterols formed during analysis. Portions of $74.4 \mu \mathrm{g}$ each of this blend were added to three samples of human plasma $(10 \mathrm{ml})$ and pair-wise compared with three samples of non-supplemented plasma. All the analyses of oxyphytosterols were carried out as described before.

\section{Results and discussion}

All plasma samples contained the same oxyphytosterols; they were identified using their retention times and by comparison of their mass spectra with those of the standards synthesised during a previous experiment (Grandgirard et al. 1999). Fig. 1 shows the full mass electronic impact spectra of $\beta$-epoxysitostanol and sitostanetriol, as well as the monitoring of some characteristic ions, corresponding to $\beta$-epoxysitostanol $(502,412)$, campestanetriol $(560$ and 470), $\alpha$-epoxysitostanol 

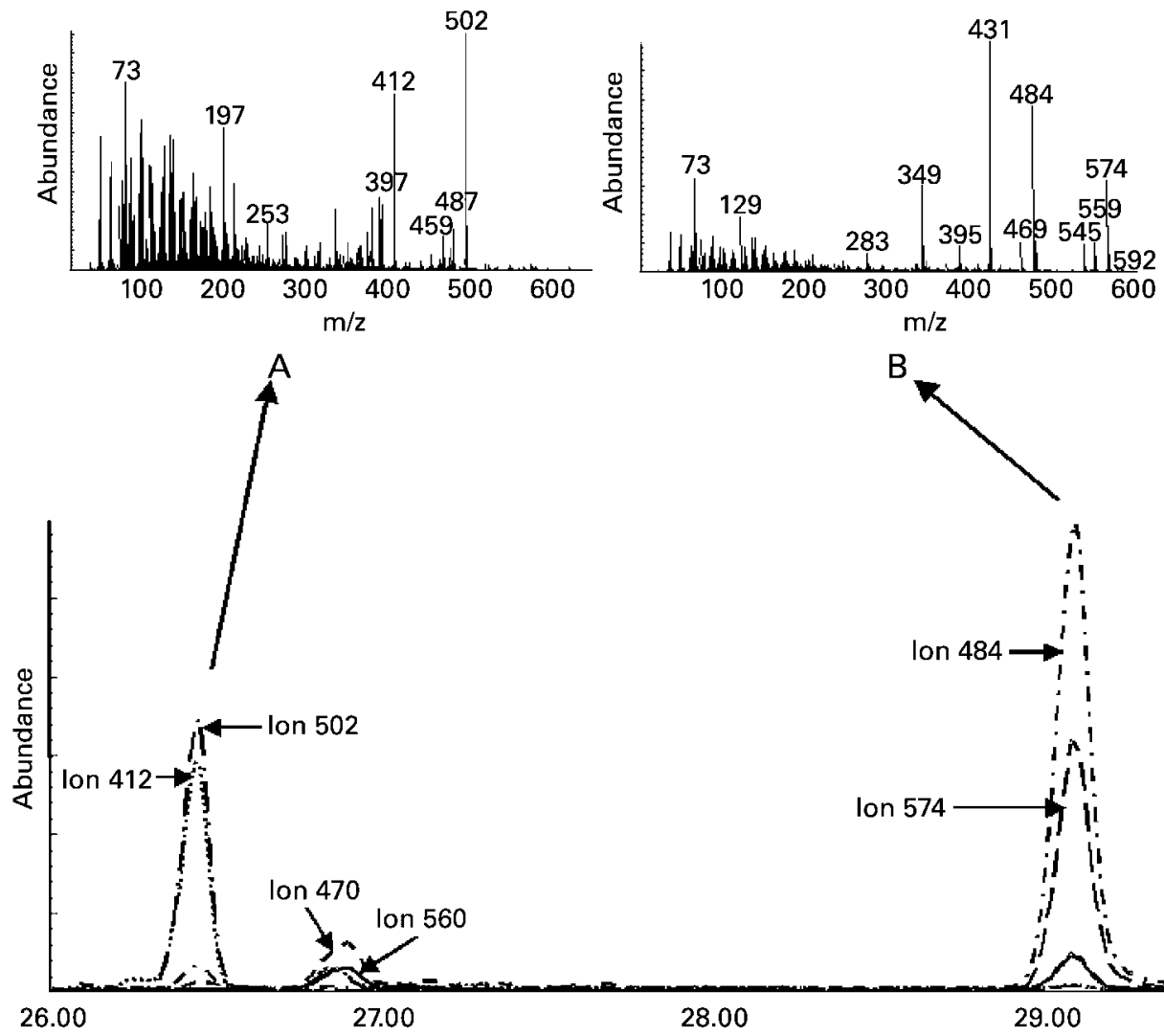

$\mathrm{m} / \mathrm{z}$

Fig. 1. Single ion monitoring of some characteristic ions obtained using electronic impact MS coupled to GC of the purified sterol oxides fraction coming from a plasma sample of a healthy human volunteer. The characteristic ions are at $\mathrm{m} / \mathrm{z} 502$ and 412 ((24R)-5 $3,6 \beta$-epoxy-24-ethyl-

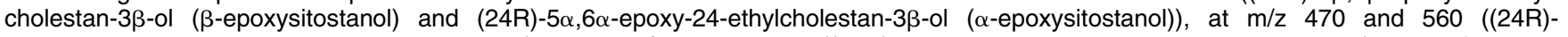

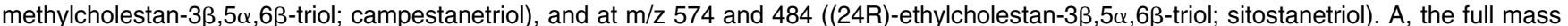
spectrum obtained at $26.43 \mathrm{~min}$ and corresponding to $\beta$-epoxysitostanol (as trimethylsilyl ether (TMSE) derivative). B, the full mass spectrum obtained at $29.06 \mathrm{~min}$ and corresponding to sitostanetriol (as TMSE derivative).

(502 and 412) and sitostanetriol $(574,484)$ as TMSE derivatives. The $\alpha$-epoxysitostanol and campestanetriol are minor compounds having close retention times with a large peak of 27-hydroxycholesterol (Fig. 2). The ions $546\left(\mathrm{M}^{+}\right), 531\left(\mathrm{M}^{+}-\mathrm{CH}_{3}\right), 456\left(\mathrm{M}^{+}\right.$-hydroxytrimethylsilyl



Fig. 2. Electronic impact mass spectrum of compounds with a retention time of $26.88 \mathrm{~min}$ (see Fig. 1) from a purified sterol oxides fraction coming from a plasma sample of a healthy human volunteer (as trimethylsilyl ether derivatives). The characteristic ions of (25R)cholest-5-en-3 $\beta, 26$-diol (27-hydroxycholesterol) are not represented on Fig. 1 to make the figure clearer. fragment (TMSOH)), $441\left(\mathrm{M}^{+}-\mathrm{TMSOH}-\mathrm{CH}_{3}\right), 417\left(\mathrm{M}^{+}\right.$129), 129 (loss characteristic of a $\Delta 5-6$ ethylenic bond), 255 and 73 come from 27-hydroxycholesterol. The ions $502\left(\mathrm{M}^{+}\right), 412\left(\mathrm{M}^{+}-\mathrm{TMSOH}\right), 394$ and 73 come from $\alpha$-epoxysitostanol. The ions $578\left(\mathrm{M}^{+}\right), 560\left(\mathrm{M}^{+}-\mathrm{H}_{2} \mathrm{O}\right)$, $545\left(\mathrm{M}^{+}-\mathrm{H}_{2} \mathrm{O}-\mathrm{CH}_{3}\right), 531,470\left(\mathrm{M}^{+}-\mathrm{H}_{2} \mathrm{O}-\mathrm{TMSOH}\right), 455$ $\left(\mathrm{M}^{+}-\mathrm{H}_{2} \mathrm{O}-\mathrm{CH}_{3}-\mathrm{TMSOH}\right), 417\left(\mathrm{M}^{+}\right.$-ring $\left.\mathrm{A}\right), 380\left(\mathrm{M}^{+}\right.$$2 \mathrm{TMSOH}-\mathrm{H}_{2} \mathrm{O}$ ) and 335 come from campestanetriol (di-TMSE derivative). As proved by Park \& Addis (1989), the derivatisation of triols in these conditions furnished the di-TMSE derivative and the molecular ion is difficult to observe. It could be remarked that some ions may come from several compounds as 417 and 73 .

A trace level of 7-ketositosterol (Fig. 3) was also detected (retention time $30.73 \mathrm{~min})$. The ions $500\left(\mathrm{M}^{+}\right)$, $485\left(\mathrm{M}^{+}-\mathrm{CH}_{3}\right), 483,444,410\left(\mathrm{M}^{+}-\mathrm{TMSOH}\right), 395\left(\mathrm{M}^{+}\right.$$\mathrm{CH}_{3}$-TMSOH), 161, 129 and 73 are characteristic of 7ketositosterol. A contaminant compound is also present (ion 130). There is also a possibility of the presence of a small quantity of $7 \beta$-hydroxysitosterol, with the same retention time as cholest-5-en-3 $\beta, 25$-diol (25-hydroxycholesterol) and an unknown compound. However this hypothesis is based only on the $\mathrm{m} / \mathrm{z} 484$ and has to be ascertained using complementary studies. The quantitative data concerning these compounds (Table 1) indicates that 




Fig. 3. Electronic impact mass spectrum of compound with a retention time of $33.7 \mathrm{~min}$ (not represented on Fig. 1) from a purified sterol oxides fraction coming from a plasma sample of a healthy human volunteer (as trimethylsilyl ether derivative).

their levels were not negligible even though they are of minor importance compared with the oxycholesterols detected in human plasma (Dzeletovic et al. 1995). However, the oxyphytosterols are rather different from the plasma oxycholesterols; they are essentially epoxides and compounds issued from epoxides such as triols. In contrast to oxycholesterols, they did not contain significant amounts of hydroxy- or keto- compounds. It is also important to note that the oxyphytosterols were almost exclusively constituted of sitosterol oxides. The campestanetriol was the only campesterol oxide in plasma and it was present at a low level. The phytosterol oxides issued from other phytosterols (stigmasterol, brassicasterol, $\Delta 5$-avenasterol, etc) were not detected.

It would probably have been very interesting to use ${ }^{2} \mathrm{H}$ labelled sitosterol for monitoring an eventual formation of artifacts, as already effected with cholesterol (Wasilchuk et al. 1992). However the only commercial compound is a blend of ${ }^{2} \mathrm{H}$-labelled phytosterols (sitosterol, campesterol, stigmasterol and probably some other minor sterols). The present authors think that the possibility of overlapping of compounds presenting the same ions in MS is very important. Then it was decided to use ${ }^{2} \mathrm{H}$-labelled cholesterol for checking the eventual formation of artifactual oxyphytosterols. There is no reason that cholesterol will be oxidised in a different manner compared with campesterol and sitosterol. The addition of ${ }^{2} \mathrm{H}$-labelled cholesterol equivalent to the amount of plasma sitosterol did not allow the observation of any ${ }^{2} \mathrm{H}$-labelled oxycholesterol. Another checking experiment was carried out by adding campesterol and sitosterol to three samples of human plasma in order to obtain a level double for sitosterol and almost double for campesterol. This did not allow the observation of an increase in oxyphytosterols. Moreover, in human plasma samples the campesterol levels are often higher than those of sitosterol (Kempen et al. 1991); in the present checking study, the level of campesterol in human plasma was 3.5 times higher than that of sitosterol. If the oxyphytosterols were artifacts, much more oxycampesterols compared with oxysitosterols would have been observed. This was not the case, and only a very small quantity of campestanetriol was observed. All these observations strengthen the opinion that these compounds are not artifacts.

The fact that these oxyphytosterols were not identified in recent studies on oxycholesterols in plasma is not very surprising. First the chromatograms of oxycholesterols always contained some unknown compounds. Then, selective ion monitoring was often used to quantify the oxycholesterols. This technique is very selective, but does not allow the identification of new compounds. Finally, in the present authors' experience, some saponification or alkaline hydrolysis techniques can be deleterious for sterol epoxides and triols (A Grandgirard and J Demaison-Meloche, unpublished results). The oxyphytosterols were previously detected only in the plasma of patients with Waldenström macroglobulinaemia (Brooks et al. 1983) or phytosterolaemia (Plat et al. 2001). In this case, the level of oxyphytosterols were very important in plasma; $2330 \mathrm{ng} \alpha$-epoxysitosterol $/ \mathrm{ml}$ in phytosterolaemic patients compared with only $5.5 \mathrm{ng}$ $\alpha$-epoxysitosterol $/ \mathrm{ml}$ and $57.2 \mathrm{ng} \beta$-epoxysitosterol $/ \mathrm{ml}$ in healthy volunteers in the present study. In the same study, Plat et al. (2001) did not identify any oxyphytosterols in control serum. However, they used as the internal standard

Table 1. Oxyphytosterol levels in plasma samples of thirteen healthy human volunteers (ng/ml plasma) (Raw data, mean values and standard deviations)

\begin{tabular}{|c|c|c|c|c|c|}
\hline Volunteer & $\beta$-Epoxysitostanol & $\alpha$-Epoxysitostanol & Campestanetriol & Sitostanetriol & 7-Ketositosterol \\
\hline$A$ & $42 \cdot 0$ & $4 \cdot 9$ & $4 \cdot 1$ & $25 \cdot 3$ & $23 \cdot 2$ \\
\hline B & $59 \cdot 4$ & 3.5 & 6.5 & 63.5 & $3 \cdot 9$ \\
\hline $\mathrm{C}$ & $68 \cdot 2$ & $7 \cdot 7$ & $5 \cdot 5$ & $31 \cdot 8$ & $7 \cdot 7$ \\
\hline $\mathrm{D}$ & $56 \cdot 1$ & $4 \cdot 7$ & $5 \cdot 2$ & $55 \cdot 0$ & $3 \cdot 4$ \\
\hline$E$ & $65 \cdot 6$ & $5 \cdot 1$ & $4 \cdot 1$ & $28 \cdot 8$ & 2.5 \\
\hline$F$ & $76 \cdot 7$ & $5 \cdot 8$ & $7 \cdot 3$ & $69 \cdot 1$ & $10 \cdot 2$ \\
\hline $\mathrm{G}$ & $72 \cdot 2$ & $6 \cdot 0$ & 3.4 & 33.0 & $3 \cdot 7$ \\
\hline $\mathrm{H}$ & $51 \cdot 3$ & $4 \cdot 9$ & $5 \cdot 2$ & $27 \cdot 9$ & $7 \cdot 7$ \\
\hline I & $41 \cdot 8$ & $6 \cdot 0$ & $3 \cdot 9$ & $25 \cdot 4$ & $4 \cdot 7$ \\
\hline$J$ & $61 \cdot 8$ & $5 \cdot 9$ & $4 \cdot 3$ & $62 \cdot 7$ & $5 \cdot 3$ \\
\hline $\mathrm{K}$ & $62 \cdot 7$ & $6 \cdot 9$ & $4 \cdot 3$ & $26 \cdot 7$ & $3 \cdot 2$ \\
\hline $\mathrm{L}$ & $43 \cdot 1$ & $3 \cdot 7$ & 2.8 & $27 \cdot 8$ & n.d. \\
\hline M & $42 \cdot 5$ & $6 \cdot 2$ & $5 \cdot 7$ & $31 \cdot 3$ & 3.7 \\
\hline Mean & $57 \cdot 2$ & 5.5 & $4 \cdot 8$ & 39.1 & $6 \cdot 1$ \\
\hline SD & $12 \cdot 1$ & $1 \cdot 2$ & $1 \cdot 3$ & $16 \cdot 7$ & $5 \cdot 7$ \\
\hline
\end{tabular}

n.d., not detected. 
a blend of multi- ${ }^{2} \mathrm{H}$-labelled oxyphytosterols (6.5 to $8.9 \% \mathrm{~d}_{0}$; 3.9 to $4.2 \% \mathrm{~d}_{1} ; 7.3$ to $9.2 \% \mathrm{~d}_{2} ; 20.3$ to $21.2 \% \mathrm{~d}_{3} ; 29.8$ to $31.9 \% \mathrm{~d}_{4} ; 22.4 \% \mathrm{~d}_{5} ; 2.7$ to $5.7 \% \mathrm{~d}_{6} ; 1.8$ to $\left.1.9 \% \mathrm{~d}_{7}\right)$. The blend was obtained from a mixture of phytosterols (sitosterol, campesterol, stigmasterol and probably some other minor sterols). This did not allow a sensitive and precise quantification, due to the overlapping of compounds presenting the same ions in MS. They indeed described a limit of detection of 0.41 to $0.83 \mu \mathrm{g} / \mathrm{ml}$ compared with 0.4 to $0.9 \mathrm{ng}$ for $10 \mathrm{ml}$ plasma in the present study. This could explain the apparent discrepancies between the two studies.

The source of these plasma oxyphytosterols is actually difficult to establish. The diet origin is possible; these compounds are formed in food and can be absorbed in small quantities. In rats, Grandgirard et al. (1999) observed a lower absorption of 7-ketophytosterols compared with epoxy derivatives; the low levels of 7-ketositosterol (and the absence of 7-ketocampesterol) observed in human plasma could be partly due to their low absorption. But it is also possible that they could be readily metabolised, as observed for 7-ketocholesterol (Lyons et al. 1999). In vitro, the microsomal transformation of $\beta$-epoxysitostanol in sitostanetriol was shown as less efficient than that of $\alpha$-epoxysitostanol (Aringer \& Eneroth, 1974). This could explain the low level of $\alpha$-epoxysitostanol compared with $\beta$-epoxysitostanol in human plasma. However in the same study, Aringer \& Eneroth (1974) showed that the $\beta$-epoxides were formed in three- to four-fold excess over the $\alpha$-epoxides; this could be a sign that the observed oxyphytosterols are formed in vivo from the corresponding non-oxidised phytosterols. Further studies are necessary to conclude on this point. The fact that the oxycampesterols are observed only as traces compared with oxysitosterols could be explained by a higher metabolic rate.

In some cases, cholestanetriol is pointed out as one of the more cytotoxic oxysterols (Peng et al. 1979) and its involvement in atherosclerosis has been considered (Jacobson et al. 1985; Matthias et al. 1987). It could be interesting to know if the phytosterol-derived triols observed in human plasma have the same biological properties. Finally, it would be interesting to investigate whether a larger consumption of phytosterols can lead to an increase of oxyphytosterols in human plasma. This point will be the matter of new experiments.

\section{Acknowledgement}

The authors thank Dr M. Lefort (Laboratoire Régional de Biologie Médicale, Dijon, France) for his help in blood collection from human volunteers.

\section{References}

Addis PB (1986) Occurrence of lipid oxidation products in foods. Food Chem Toxicol 24, 1021-1030.

Aringer L \& Eneroth P (1974) Formation and metabolism in vitro of 5,6-epoxides of cholesterol and beta-sitosterol. J Lipid Res 15, 389-398.
Breuer O \& Bjorkhem I (1995) Use of an 18-O(2) inhalation technique and mass isotopomer distribution analysis to study oxygenation of cholesterol in rat - evidence for in vivo formation of 7-oxo-, 7 beta-hydroxy-, 24-hydroxy-, and 25-hydroxycholesterol. J Biol Chem 270, 20278-20284.

Brooks CJW, McKenna RM, Cole WJ, MacLachlan J \& Lawrie TDV (1983) "Profile" analysis of oxygenated sterols in plasma and serum. Biochem Soc Trans 11, 700-701.

Daly GG, Finocchiaro ET \& Richardson T (1983) Characterization of some oxidation products of beta-sitosterol. J Agric Food Chem 31, 46-50.

Diczfalusy U (2002) Origin and content of cholesterol oxidation products in biological samples. In Cholesterol and Phytosterol Oxidation Products. Analysis, Occurrence, and Biological Effects, pp. 217-240 [PC Guardiola, PC Dutta, R Codony and GP Savage, editors]. Champaign, IL: AOCS Press.

Dutta PC (1997) Studies on phytosterol oxides. 2 Content in some vegetable oils and in French fries prepared in these oils. $J \mathrm{Am}$ Oil Chem Soc 74, 659-666.

Dutta PC \& Appelqvist LA (1997) Studies on phytosterol oxides 1 Effect of storage on the content in potato chips prepared in different vegetable oils. J Am Oil Chem Soc 74, 647-657.

Dutta PC \& Savage GP (2002) Formation and content of phytosterol oxidation products in foods. In Cholesterol and Phytosterol Oxidation Products. Analysis, Occurrence, and Biological Effects, pp. 319-334 [PC Guardiola, PC Dutta, R Codony and GP Savage, editors]. Champaign, IL: AOCS Press.

Dzeletovic S, Breuer O, Lund E \& Diczfalusy U (1995) Determination of cholesterol oxidation products in human plasma by isotope dilution mass spectrometry. Anal Biochem 225, 73-80.

Emanuel HA, Hassel CA, Addis PB, Bergmann SD \& Zavoral JH (1991) Plasma cholesterol oxidation products (oxysterols) in human subjects fed a meal rich in oxysterols. J Food Sci 56, 843-847.

Garcia-Cruset S, Carpenter KLH, Codony R \& Guardiola F (2002) Cholesterol oxidation products and atherosclerosis. In Cholesterol and Phytosterol Oxidation Products. Analysis, Occurrence, and Biological Effects, pp. 241-277 [PC Guardiola, PC Dutta, R Codony and GP Savage, editors]. Champaign, IL: AOCS Press.

Giacometti J (2001) Determination of aliphatic alcohols, squalene, alpha-tocopherol and sterols in olive oils: direct method involving gas chromatography of the unsaponifiable fraction following silylation. Analyst 126, 472-475.

Grandgirard A, Sergiel JP, Nour M, Demaison-Meloche J \& Ginies C (1999) Lymphatic absorption of phytosterol oxides in rats. Lipids 34, 563-570.

Guardiola F, Codony R, Addis PB, Rafecas M \& Boatella J (1996) Biological effects of oxysterols: current status. Food Chem Toxicol 34, 193-211.

Jacobson MS, Price MG, Shamoo AE \& Heald FP (1985) Atherogenesis in White Carneau pigeons: effects of low-level cholestane-triol feeding. Atherosclerosis 57, 209-217.

Janowski BA, Willy PJ, Devi TR, Falck JR \& Mangelsdorf DJ (1996) An oxysterol signalling pathway mediated by the nuclear receptor LXR alpha. Nature 383, 728-731.

Kempen HJM, De Knijff P, Boomsma DI, Van Der Voort HA, Gevers Leuven JA \& Havekes L (1991) Plasma levels of lathosterol and phytosterols in relation to age, sex, anthropometric parameters, plasma lipids, and apolipoprotein-E phenotype, in 160 Dutch families. Metab Clin Exp 40, 604-611.

Lai SM, Gray JI \& Zabik ME (1995) Evaluation of solid phase extraction and gas chromatography for determination of cholesterol oxidation products in spray-dried whole egg. J Agric Food Chem 43, 1122-1126. 
Lee K, Herian AM \& Higley NA (1985) Sterol oxidation products in french fries and in stored potato chips. $J$ Food Protect 48, $158-161$

Lyons MA, Samman S, Gatto L \& Brown AJ (1999) Rapid hepatic metabolism of 7-ketocholesterol in vivo: implications for dietary oxysterols. J Lipid Res 40, 1846-1857.

Matthias D, Becker CH, Godicke W, Schmidt R \& Ponsold K (1987) Action of cholestane-3beta,5alpha,6beta-triol on rats with particular reference to aorta. Atherosclerosis 63, $115-124$.

Moilanen T \& Nikkari T (1981) The effect of storage on the fatty acid composition of human serum. Clin Chim Acta 114, $111-116$.

Nourooz-Zadeh J \& Appelqvist LA (1992) Isolation and quantitative determination of sterol oxides in plant-based foods: soybean oil and wheat flour. J Am Oil Chem Soc 69, 288-293.

Osada K, Sasaki E \& Sugano M (1994) Lymphatic absorption of oxidized cholesterol in rats. Lipids 29, 555-559.
Park PSW \& Addis PB (1989) Derivatization of 5a-cholestane3b,5,6b-triol into trimethylsilyl ether sterol for GC analysis. J Am Oil Chem Soc 66, 1632-1634.

Peng SK, Hu B \& Morin RJ (1991) Angiotoxicity and atherogenicity of cholesterol oxides. J Clin Lab Anal 5, 144-152.

Peng SK, Tham P, Taylor CB \& Mikkelson B (1979) Cytotoxicity of oxidation derivatives of cholesterol on cultured aortic smooth muscle cells and their effect on cholesterol biosynthesis. Am J Clin Nutr 32, 1033-1042.

Piironen V, Lindsay DG, Miettinen TA, Toivo J \& Lampi AM (2000) Plant sterols: biosynthesis, biological function and their importance to human nutrition. J Sci Food Agric 80, 939-966.

Plat J, Brzezinka H, Lutjohann D, Mensink RP \& von Bergmann K (2001) Oxidized plant sterols in human serum and lipid infusions as measured by combined gas-liquid chromatography-mass spectrometry. J Lipid Res 42, 2030-2038.

Wasilchuk BA, Le Quesne PW \& Vouros P (1992) Monitoring cholesterol autoxidation processes using multideuteriated cholesterol. Anal Chem 64, 1077-1087. 